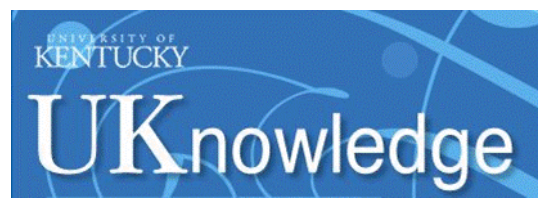

University of Kentucky

UKnowledge

\title{
Group Therapy for Incarcerated Women Who Experienced Interpersonal Violence: A Pilot Study
}

\author{
Rebekah G. Bradley \\ Emory University, rbradl2@emory.edu \\ Diane R. Follingstad \\ University of South Carolina - Columbia, follingstad@uky.edu
}

Follow this and additional works at: https://uknowledge.uky.edu/crvaw_facpub

Part of the Civil Rights and Discrimination Commons, Law and Gender Commons, Mental and Social Health Commons, Psychiatry and Psychology Commons, and the Social Work Commons

Right click to open a feedback form in a new tab to let us know how this document benefits you.

\section{Repository Citation}

Bradley, Rebekah G. and Follingstad, Diane R., "Group Therapy for Incarcerated Women Who Experienced Interpersonal Violence: A Pilot Study" (2003). CRVAW Faculty Journal Articles. 61.

https://uknowledge.uky.edu/crvaw_facpub/61

This Article is brought to you for free and open access by the Center for Research on Violence Against Women at UKnowledge. It has been accepted for inclusion in CRVAW Faculty Journal Articles by an authorized administrator of UKnowledge. For more information, please contact UKnowledge@lsv.uky.edu. 
Group Therapy for Incarcerated Women Who Experienced Interpersonal Violence: A Pilot Study

Digital Object Identifier (DOI)

http://dx.doi.org/10.1023/A:1024409817437

Notes/Citation Information

Published in Journal of Traumatic Stress, v. 16, no. 4, p. 337-340.

Dr. Diane Follingstad had not been a faculty member of the University of Kentucky at the time of publication. 


\title{
Group Therapy for Incarcerated Women Who Experienced Interpersonal Violence: A Pilot Study
}

\author{
Rebekah G. Bradley ${ }^{1,3}$ and Diane R. Follingstad ${ }^{2}$
}

\begin{abstract}
This study evaluated effectiveness of group therapy for incarcerated women with histories of childhood sexual and/or physical abuse. The intervention was based on a two-stage model of trauma treatment and included Dialectical Behavior Therapy skills and writing assignments. We randomly assigned 24 participants to group treatment (13 completed) and 25 to a no-contact comparison condition (18 completed). We evaluated treatment effects, using the Beck Depression Inventory, Inventory of Interpersonal Problems, and Trauma Symptom Inventory. The data demonstrate significant reductions in PTSD, mood, and interpersonal symptoms in the treatment group.
\end{abstract}

KEY WORDS: interpersonal victimization; women; incarceration; treatment outcome; group therapy.

The frequency of childhood physical and sexual abuse among incarcerated women is higher than that in the general population and often involves severe, multiple abuse experiences with early onset (Browne, Miller, \& Maguin, 1999). Estimates of lifetime experience of physical or sexual assault among incarcerated women range from 43 to $75 \%$ (Browne et al., 1999). Incarcerated women with experiences of trauma report symptoms including depression, PTSD, borderline personality disorder (BPD), and substance abuse (Jordan, Shelenger, Fairbank, \& Caddell, 1996).

Brown, Schefflin, and Hammond (1998) recommend that trauma treatment follow a stage-based approach: the first phase focuses on increased safety/stabilization (e.g., psychological skills for the regulation of emotions) and the second phase focuses on integration through retelling of past traumatic events. Research with incarcerated women

\footnotetext{
${ }^{1}$ Department of Psychology, Southern Illinois University - Carbondale, Carbondale, Illinois.

${ }^{2}$ Psychology Department, University of South Carolina, Columbia, South Carolina.

${ }^{3}$ To whom correspondence should be addressed at 1462 Clifton Road, Psychological Center, Suite 235, Atlanta, Georgia 30322; e-mail: rbrad12@emory.edu.
}

suggests that skills training effectively addresses selfesteem, perceived control, trust in others and symptoms of depression, anxiety, and PTSD (Pomeroy, Kiam, \& Abel, 1999; Sultan \& Long, 1988). Skills-based approaches for survivors of interpersonal violence have also been effective (Rothbaum, Meadows, Resick, \& Foy, 2000). Given the high rates of mood-related disorders and disorders related to impulse control and affect regulation (e.g., substance abuse and BPD) among incarcerated women, this study evaluated a treatment-based Dialectical Behavior Therapy (Linehan, 1993).

Both directed exposure (Rothbaum et al., 2000) and writing about traumatic events (see Esterling, L'Abate, Muray, \& Pennebaker, 1999, for a review) have empirical support as potential approaches for the integration phase of treatment. In two pilot groups we conducted, incarcerated women felt vulnerable to becoming overwhelmed by emotions and expressed a high need for control over the extent to which they discussed experiences of interpersonal violence. Therefore, we chose a writing-based approach focused on the development of a coherent life story, placing traumatic experiences in context, encouraging integration of positive and negative experiences, and increasing cause-and-effect connections. We hypothesized that group treatment combining skills and writing would decrease 
mood- and trauma-related symptoms among incarcerated trauma survivors.

\section{Method \\ Participants}

Participants were selected from a larger sample of 165 incarcerated women in a medium security prison in a Southeastern state. Ninety-seven met inclusion criteria, and 49 were willing to participate in the study. Those participating did not differ significantly from those not participating on demographic variables. Primary reasons for not participating included (1) another commitment (e.g., work, school), (2) involvement in another treatment program, or (3) not wanting to participate in a group in the prison setting (i.e., did not trust other women they might have contact with outside of group). Participants completed informed consent allowing referral to the treatment group and again prior start of group. Inclusion criteria included self-reported childhood abuse and significant impairment ( $t$ scores higher than 65) on two or more scales of the Trauma Symptom Inventory (TSI) or on one scale of the TSI along with a score of 18 or higher on the Beck Depression Inventory (BDI).

Sixty-two percent of participants were African American and $38 \%$ were White. All of the women reported childhood sexual abuse, $71 \%$ childhood physical abuse, $83 \%$ adult sexual assault, $90 \%$ adult sexual assault, and $65 \%$ all four types of interpersonal victimization. Participants' ages ranged from 34 to 54 ( $M=36.67$, $S D=8.27$.

\section{Measures}

We interviewed women about three types of nonconsensual contact sexual experiences (i.e., intercourse, oral sex, touching) during childhood (under 18 years) and adulthood. We assessed histories of physical assault in child and adult relationships, using the Conflict Tactics Scale (Straus, 1990). Childhood physical abuse was defined by being hit with an open hand harder than a slap or spank at least three times, or more severe violence by caregivers. Adult physical abuse was defined by being hit with an open hand harder than a slap at least three times, hit with a fist at least three times, or more severe violence by a romantic partner. These criteria were similar to those used by Straus (1990) with the exception that somewhat stricter inclusion criteria were used because of the high base rate of interpersonal victimization in this population.
Outcome assessments were completed prior to the first session and 1 week after conclusion of treatment. The BDI is a 21-item self-report measure assessing severity of depression (Beck, Steer, \& Brown, 1996). The TSI yields 10 clinical scales assessing sequelae of traumatic events. We did not use three scales because of questions about sexual behavior not expected to be valid in the prison context. The TSI scales used included Anxious Arousal, Depression, Anger/Irritability, Intrusive Experiences, Defensive Avoidance, Dissociation, and Impaired Self-Reference. The TSI has shown reliability and validity in assessing long-term impact of a wide range of traumas, including interpersonal violence (Briere, 1995). The Inventory of Interpersonal Problems (IIP-32) assesses interpersonal problems common in clinical populations (Barkham, Hardy, \& Startup, 1994).Treatment adherence was assessed with therapists' case/process notes.

\section{Design and Procedure}

Participants were randomly assigned to treatment or no-contact comparison groups. Of 24 women initially assigned to the treatment condition; four were paroled or sent to another facility prior to completing the group, two dropped out after the first session, and the rest dropped out after completing the first $(n=3)$ or second $(n=2)$ of the sessions focused on writing assignments. Of the 13 women who completed the group, 12 attended at least 15 of the 18 sessions. One participant attended 10 of the 18 sessions because of scheduling conflicts, but she worked closely with another member to review the material she missed and she completed all of the assignments. We assigned 25 women to the comparison condition. Five were paroled or sent to another facility and two dropped out because of scheduling conflicts.

Group sessions were $2.5 \mathrm{hr}$. Nine treatment sessions focused on education about interpersonal victimization and affect regulation (e.g., identifying and naming emotions and precipitating factors; using breathing exercises to decrease distress). The skills were based on Linehan's DBT model (Linehan, 1993) and one of the leaders for each group had completed a 40-hr DBT training. Nine sessions focused on structured writing assignments. We encouraged women to create meaningful narratives of their life experiences, including interpersonal victimization. The writing assignments asked women to describe specific times in their lives (e.g., write about your childhood) and included specific prompts (e.g., write about relationships in your family; write about some of the best and worst things that happened to you growing up). We encouraged women to use these as guidelines in writing a "whole story" and to make connections between past life 
Table 1. Reported Symptoms at Pre and Posttreatment

\begin{tabular}{|c|c|c|c|c|c|c|c|}
\hline \multirow[b]{2}{*}{ Measure } & \multirow[b]{2}{*}{ Group } & \multicolumn{2}{|c|}{ Pretest } & \multicolumn{2}{|c|}{ Posttest } & \multirow[b]{2}{*}{ Effect size } & \multirow[b]{2}{*}{$F($ group $\times$ time $)$} \\
\hline & & $M$ & $S D$ & $M$ & $S D$ & & \\
\hline \multirow[t]{2}{*}{ BDI } & Treat & 23.8 & 11.6 & 11.7 & 10.3 & 1.15 & $4.9^{*}$ \\
\hline & NCC & 21.9 & 14.3 & 18.6 & 15.5 & 0.22 & \\
\hline \multirow[t]{2}{*}{ IIP } & Treat & 47.7 & 20.3 & 33.3 & 17.6 & 0.75 & $21.9^{*}$ \\
\hline & NCC & 46.9 & 24.8 & 43.4 & 23.1 & 0.15 & \\
\hline \multirow[t]{2}{*}{ TSI—Depression } & Treat & 62.6 & 7.9 & 53.1 & 11.0 & 1.0 & $7.2^{* *}$ \\
\hline & NCC & 56.6 & 10.6 & 55.9 & 12.6 & 0.06 & \\
\hline \multirow{2}{*}{ TSI_Anxious Arousal } & Treat & 64.4 & 11.7 & 55.5 & 14.3 & 0.68 & $4.8^{*}$ \\
\hline & NCC & 58.8 & 13.3 & 58.1 & 13.9 & 0.05 & \\
\hline \multirow{2}{*}{ TSI-Intrusive Experiences } & Treat & 66.5 & 8.8 & 56.6 & 11.1 & 1.0 & $14.2^{* *}$ \\
\hline & NCC & 60.0 & 12.1 & 61.9 & 11.6 & -0.16 & \\
\hline \multirow[t]{2}{*}{ TSI-Defensive Avoidance } & Treat & 65.5 & 8.0 & 59.3 & 8.5 & 0.75 & $1.59(n s)$ \\
\hline & NCC & 61.6 & 8.5 & 58.9 & 8.4 & 0.32 & \\
\hline \multirow[t]{2}{*}{ TSI—Anger and Irritability } & Treat & 61.6 & 10.7 & 53.5 & 10.9 & 0.75 & $5.0^{*}$ \\
\hline & NCC & 58.1 & 10.3 & 56.6 & 11.0 & 0.14 & \\
\hline \multirow[t]{2}{*}{ TSI_Dissociation } & Treat & 65.3 & 12.1 & 54.4 & 11.1 & 0.94 & $5.1^{*}$ \\
\hline & NCC & 59.9 & 12.4 & 56.9 & 10.2 & 0.27 & \\
\hline \multirow[t]{2}{*}{ TSI-Impaired Self-Reference } & Treat & 61.5 & 9.0 & 51.2 & 8.1 & 1.21 & $10.3^{* *}$ \\
\hline & NCC & 57.1 & 10.4 & 55.7 & 9.1 & 0.14 & \\
\hline
\end{tabular}

Note. Treat, Treatment group; NCC, No Contact Control group; BDI, Beck Depression Inventory; IIP, Inventory of Interpersonal Problems; TSI, Trauma Symptom Inventory. Treat, $n=13 ; \mathrm{WL}, n=18$. Effect size $=$ pretest-posttest/pooled $S D$.

${ }^{*} p<.05 .{ }^{* *} p<.01$.

events and current feelings (e.g., write about how your younger self came to be your adult self). Some of the writing assignments focused on issues expected to be particularly salient to incarcerated women (e.g., anger).

Although none of the women were required to write about any specific incident of victimization (the leaders encouraged writing a story with a beginning middle and end that included both positive and negative experiences and "made sense" to the writer), all of the women who completed the group did refer to experiences of interpersonal victimization in their writing assignments, although few described one event in detail. More commonly women developed descriptions of their experiences over the course of the writing assignments (e.g., wrote that they had been raped by a family member when writing about childhood experiences, about being assaulted by a spouse when writing about adult experiences, about their anger about being harmed in a later assignment). We used time in group sessions for completion of writing assignments (many women wrote between groups) and shared writings in group (although some women did not feel comfortable reading all of their writings to others and only read a portion). Three consecutive treatment groups were coled by female clinical psychology doctoral students using a treatment manual developed by the first author.

\section{Results}

There were no significant differences, across dependent variables, between the completers and noncompleters,
Wilk's $\Lambda=.74, F(9,14)=0.53, n s$, and treatment and comparison group at pretest Wilk's $\Lambda=0.79, F(9,22)=$ $0.72, n s$. A repeated measures MANOVA yielded a significant overall Group $\times$ Time interaction, Wilk's $\Lambda=0.41$, $F(9,21)=3.40, p<.01$. Follow-up repeated measures ANOVAs indicated significant interactions on all dependent variables except the TSI Defensive Avoidance scale. The average pre-post effect sizes for the treatment group were in the moderate-to-large range whereas those for the comparison group were in the average-to-small range (see Table 1).

\section{Discussion}

The results of this study provide some support for the effectiveness of a treatment combining psychosocial skills and writing. There were clinically significant decreases in depression (from severely to mildly depressed as measured by the BDI) and on the Dissociation, Anxious Arousal, and Intrusive Experiences scales of the TSI (symptoms for the treatment group started at $t=65$ and dropped $1 S D$ below clinical level). These results are consistent with other work on the effectiveness of skills training (e.g., with incarcerated women and women with affect regulation difficulties) and writing about past traumatic experiences. The decrease across several scales of the TSI and the BDI suggest that the combination of skills and writing about life experiences may be effective in reducing global symptoms of affect regulation and negative 
affect associated with experiences of interpersonal violence. Because PTSD was not directly assessed, and because the writing assignments did not specifically address a given traumatic event, this treatment should be viewed in the broader context of symptoms associated with experiences of interpersonal violence, rather than as a PTSDfocused treatment.

A significant limitation of the study is the no-contact comparison group, making results nonattributable to specific components of the treatment as opposed to the group process and support/contact. Future studies should compare this type of intervention to another active intervention. Also the women were screened for history of interpersonal violence using an interview method rather than having history of abuse corroborated by an outside authority such as hospital or child protective agency records. Another limitation is the high dropout rate. Any positive outcomes of the intervention must be considered in light of the fact that half of the women could be considered treatment failures. However, this study included women (i.e., incarcerated, minority, history of multiple traumas, difficulty regulating affect, history of substance use) who are generally not included in treatment outcome studies or seen as appropriate for therapy. Further, in therapy process notes, group leaders indicated that women who dropped out appeared to be less able to tolerate intense emotions. Future studies should examine the extent to which different treatment approaches and participant characteristics predict dropout. It is also noteworthy that of the seven women who quit coming to treatment for reasons other than parole/transfer, five quit in the first two sessions of the writing component. More affect regulation skills prior to the writing component may have been needed. It is hoped that this study will provide a starting point for further development and evaluation of interventions for incarcerated women.

\section{References}

Barkham, M., Hardy, G. E., \& Startup, M. (1994). The structure, validity and clinical relevance of the Inventory of Interpersonal Problems. British Journal of Medical Psychology, 67, 171-185.

Beck, A. T., Steer, R. A., \& Brown, G. K. (1996). Beck Depression Inventory Manual (2nd ed.). San Antonio, TX: The Psychological Corporation.

Briere, J. (1995). Trauma Symptom Inventory (TSI) professional manual. Odessa, FL: PAR

Browne, A., Miller, B., \& Maguin, E. (1999). Prevalence and severity of lifetime physical and sexual victimization among incarcerated women. International Journal of Law and Psychiatry, 22, 301-322.

Brown, D., Schefflin, A. W., \& Hammond, D. C. (1998). Memory, trauma treatment and the law. New York: W.W. Norton.

Esterling, B. A., L'Abate, L., Muray, E. J., \& Pennebaker, J. W. (1999). Empirical foundations for writing in prevention and psychotherapy: Mental and physical health outcomes. Clinical Psychology Review, 19, 79-96.

Jordon, B. K., Shelenger, W. E., Fairbank, J., \& Caddell, J. (1996). Prevalence of psychiatric disorders among incarcerated women: Convicted felons entering prison. Archives of General Psychiatry, 53, 513-519.

Linehan, M. (1993). Cognitive behavioral treatment of borderline personality disorder. New York: Guilford Press.

Pomeroy, E. C., Kiam, R., \& Abel, E. M. (1999). The effectiveness of a psychoeducational group for HIV-infected/affected incarcerated women. Research on Social Work Practice, 9, 171-187.

Rothbaum, B. O., Meadows, E. A., Resick, P., \& Foy, D. W. (2000). Cognitive-behavioral therapy. In E. B. Foa, T. M. Keane, \& M. J. Friedman (Eds.), Effective treatments for PTSD (pp. 320-325). New York: Guilford Press.

Straus, M. A. (1990). The conflict tactics scale and its critics: An evaluation of new data on validity and reliability. In M. A. Straus and R. J. Gelles (Eds.), Physical violence in the American family (pp. 49-73). New Brunswick, NJ: Transaction Books.

Sultan, F. E., \& Long, G. T. (1988). Treatment of sexually/physically abused female inmates: Evaluation of an intensive short-term program. Journal of Offender Counseling, Services, and Rehabilitation, 12, 131-143. 